\title{
International safety standards and supporting projects related to demonstrating the safety of radioactive waste disposal facilities
}

\author{
P. Metcalf and D. Louvat \\ International Atomic Energy Agency, Vienna, Austria
}

\begin{abstract}
The paper elaborates on the international safety standards related to demonstrating the safety of radioactive waste disposal and provides on overview of the intercomparaison and harmonization projects presently underway.
\end{abstract}

\section{THE FRAMEWORK FOR SAFETY DEMONSTRATION}

The IAEA programme on radioactive waste management sets up and promotes a universally applicable global waste safety regime for use by the IAEA Member States in their own programmes and to resolve issues with their neighbours. The objective of the programme is to achieve global harmonization in policies, criteria and standards governing waste safety and public and environmental protection, together with provisions for their application including state of the art technologies and methods for demonstrating their adequacy.

\subsection{The Global Nuclear Safety Regime}

The Global Nuclear Safety Regime has been defined by the International Nuclear Safety Group [1] as the institutional, legal and technical framework for ensuring the safety of nuclear installations with the objective to lead to a world where all nuclear installations are operating safely. Applied to radioactive waste management, the global nuclear safety regime includes the legally binding international agreement to maintain a high level of safety through an international review process between countries party to the Joint Convention on the Safety of Spent Fuel Management and the Safety of Radioactive Waste Management. This regime is supported by the International Safety Standards and by their use and application in IAEA Member States through advisory services, peer reviews and training programmes.

\subsection{The international safety standards}

The IAEA is mandated to develop and maintain international safety standards for nuclear, radiation, radioactive waste and radioactive material transport safety. The standards are developed in a hierarchical suite of documents headed by a single standard on fundamental safety principles; applicable to all facilities and activities, and covering all circumstances. The next tier of standards sets out requirements to fulfil these principles for different facilities and activities, and the third tier standards provides guidance on meeting the requirements. The guidance is being continually updated with a view to capturing and representing best prevailing practice. 


\section{THE SAFETY OF RADIOACTIVE WASTE DISPOSAL}

\subsection{Fundamentals safety principles}

The need to assess and demonstrate that facilities and activities will be safe is ensconced in the 10 principles enounced into the IAEA Safety Fundamentals [2]. The key principle for Radioactive Waste Management is Principle 7 on the protection of present and future generations which states that people and the environment, present and future, must be protected against radiation risks. This means that radioactive waste must be managed in such a way as to avoid imposing an undue burden on future generations and that the generations that produce the waste have to apply safe, practicable and environmentally acceptable solutions for its long term management. In the explanatory section of Principle 7, it is recognized that whereas the effects of radiation exposure on human health are relatively well understood, the effects of radiation on the environment have been less thoroughly investigated. However, the present system of radiation protection generally provides appropriate protection of ecosystems in the human environment against harmful effects of radiation exposure.

\subsection{Safety requirements for radioactive waste disposal}

At present there are two Safety Requirements standards, one which addresses near surface disposal facilities [3] and one Safety Requirements document for geological disposal [4]. There are no Safety Requirements for the other types of waste disposal facilities however in developing the Safety Requirements on geological disposal it did appear that many of the requirements would be applicable to all types of disposal facilities. In the interests of coherence, it was therefore decided to prepare a single Safety Requirements for all types of disposal facilities combining together the two existing standards.

The primary goal of disposal is the protection of human health and the environment in the long term, after the disposal facility has been closed. Constrained optimization is the central approach adopted to ensure the radiological safety of a waste disposal facility [5]. In this context, the optimization of protection is a judgemental process, with social and economic factors being taken into account, undertaken in a structured but essentially qualitative manner, supported by quantitative analysis. The standard recognizes that radiation doses to individuals in the future can only be estimated and that the uncertainties associated with these estimates will increase for times farther into the future. Additionally care needs to be exercised in using the criteria beyond the time where the uncertainties become so large that the criteria may no longer serve as a reasonable basis for decision making. It is assumed that the protection of humans against the radiological hazards associated with a disposal facility will also satisfy the principle of protecting the environment. Dose estimates to humans that take account of a range of possible environmental transfer pathways could already be considered as indicators of environmental protection. Additional indicators and comparisons, such as estimates of the concentrations and fluxes of contaminants and their comparison with the concentrations and fluxes of naturally occurring radionuclides, may also prove valuable to indicate a level of overall environmental protection that is independent of assumptions about human habits. Other factors to be considered may include the protection of groundwater resources and the ecological sensitivity of the environment into which contaminants may be released.

In the Requirements Standards under preparation, three requirements call for safety cases and supporting safety assessment to be carried out and maintained current for all types of radioactive waste disposal facilities: a requirement on preparation of the safety case and safety assessment; a requirement on scope of the safety case and safety assessment and a requirement on documentation of the safety case and safety assessments. The development of a safety case and supporting safety assessments for review by the regulator and other interested parties are central to the development, operation and closure of a disposal facility. The safety case is intended to substantiate the safety, and to contribute to confidence in the safety, of the disposal facility. The safety case is an essential input to all the 
important decisions concerning the facility. Safety assessment is the process of systematically analysing the hazards associated with the facility and the ability of the site and the design of the facility to provide for the safety functions and to meet technical requirements. Depending on the stage of development, safety assessments may be used to aid in focusing research, and their results may be used to assess compliance with the various safety objectives and standards.

\subsection{Safety guides for radioactive waste disposal}

The Safety Requirements standards are complemented by a series of facility specific Safety Guides. These guides present guidance and recommendations on best practice to comply with the requirements for different types of disposal facilities (near surface disposal, geological disposal, borehole disposal... ). The guides address site selection and characterisation, design, development, operation and closure of facilities. They also provide guidance on meeting requirements for the safety case and supporting safety assessment and for management systems to assure the quality of safety related work for the particular types of facilities. In addition a specific suide on the safety case and safety assessment was developed in 2007 and it is undergoing review by Member States of the IAEA, with a view to developing international consensus on this matter. The objective of this Safety Guide is to provide guidance on how to assess, support and document the safety arguments and evidence for radioactive waste disposal facilities. It identifies the most important considerations when assessing the safety of radioactive waste disposal facilities and provides guidance on best practice in undertaking such assessments and presenting safety cases. It also provides guidance on the development and review of safety cases for radioactive waste disposal facilities. The guide covers the development of safety cases and safety assessments for all types of solid radioactive waste that require specialised disposal facilities. It discusses all steps in the development of a disposal facility. It emphasizes issues associated with the assessment of post-closure performance and impacts. The Safety Guide also touches on the involvement of stakeholders, issues of risk communication and approaches to decision making; as these are essential components of safety case development and use.

An important section of the guide elaborates on the concept of the safety case. The components of the safety case and its role during the development, operation and closure of a disposal facility are described, and possibilities for building confidence in the safety case are discussed. Another section addresses the methodology for conducting safety assessment, which forms an important element of the safety case. Different steps in this process are outlined and discussed in detail. In particular, the management of uncertainties within a safety assessment is addressed, as well as the use of the outcome of the safety assessment for comparison with assessment criteria. Guidance is also provided on integrating safety assessment results within the safety case. It also addresses safety case documentation, and indicates possible uses of the safety case in the design and operation of the disposal facility. The last section provides guidance on the regulatory review of safety assessments and safety cases.

\section{HARMONIZING SAFETY DEMONSTRATION}

To support the use of the standards, a number of international intercomparison and harmonization projects are underway, which provide a platform for countries to discuss and compare approaches and work towards the development of harmonized approaches to demonstrating the safety of radioactive waste disposal. This intercomparaison programme started as international projects on radioecological assessment and modelling that were aimed at refining existing information and to improve models to be applied for the purposes of radiation protection of the public and the environment. With the same idea and to promote safety assessment methodologies, the IAEA launched, in 1997, a project on Improving Long Term Safety Assessment Methodologies for Near Surface Radioactive Waste Disposal Facilities (ISAM). The main outcome of the project, which was completed in 2000, was the establishment of a harmonized methodology for carrying out post-closure safety assessment of near 
surface disposal facilities. Since then, the IAEA has built a coherent structure of intercomparaison projects on safety assessment methodologies and models. The Agency's project, Safety Assessment Driving Radioactive Waste Management Solutions (SADRWMS) is an international programme of work to examine international approaches to safety assessment in aspects of predisposal radioactive waste management, including waste conditioning and storage. The SADRWMS project is intended to encompass a broad range of waste types, including operational waste and spent fuel, legacy and decommissioning waste, and NORM residues. A follow up project to ISAM on Application of Safety Assessment Methodologies for Near-Surface Radioactive Waste Disposal Facilities (ASAM) was launched in 2002. It built on the experience gained with the ISAM programme, with special emphasis on application of the ISAM methodology to practical problems of near surface disposal, such as development of design concepts, safety reassessment and upgrading of existing facilities. The project on Evaluation and Demonstration of the Safety of Decommissioning of Nuclear Facilities (DeSa) has developed a harmonized methodology for evaluating and demonstrating safety during decommissioning and to produce model safety assessments for selected nuclear facilities by applying this methodology. The Environmental Modelling for Radiation Safety project (EMRAS) continues some of the work of BIOMASS. The overall objective of EMRAS, which ended in 2007, was to enhance the capabilities of Member States to model radionuclide transfer in the environment and, thereby, to assess exposure levels of the public and biota in order to ensure an appropriate level of protection from the effects of ionizing radiation, associated with radionuclide releases and from existing radionuclides in the environment.

The ISAM methodology for safety assessment [6] is outlined in Figure 1 and has provided a framework for the subsequent ASAM, SADRWMS and DeSa projects. It includes the following key components: Specification of the assessment context; Description of the waste disposal system; Development and justification of scenarios; Formulation and implementation of models; Performing simulations and analysing the results, including sensitivity and uncertainty analyses; Comparison against assessment criteria; and Review and modification of the assessment if necessary (iteration).

The ASAM project confirmed that the ISAM methodology provides a good framework for conducting safety assessment calculations. The framework provided by the methodology is sufficiently

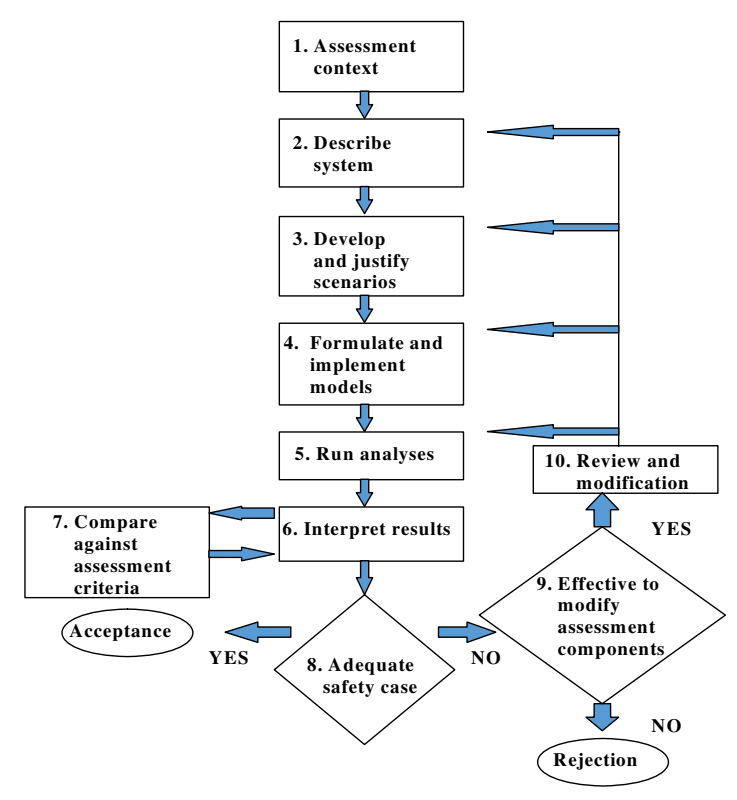

Figure 1. The ISAM Safety Assessment Methodology [6]. 
flexible that it can be applied and tailored to suit a wide range of waste disposal problems, using a range of different approaches for the treatment of uncertainty. In principle, the assessment framework is also suitable for considering the impacts of non-radioactive contaminants.

On the other hand, the ASAM project has identified the limitations of the ISAM assessment methodology as currently formulated. The main limitations lie in the area of the use of safety assessment for informing practical decisions about alternative waste and risk management strategies/activities at real disposal sites. At a more detailed level guidance has been developed on several important safety assessment issues (disruptive events, engineered barriers, conservatism and realism, how to deal with a lack of site-specific information, review of safety assessment, decision-analysis), and many other specific lessons have been learnt relating to the individual steps in the assessment methodology.

The ASAM project has also led to increased understanding amongst the low-level radioactive waste management and disposal community of the safety case and of its importance and role in informing decisions on the regulation and operation of disposal facilities. Whilst safety assessment forms a central part of safety case, the safety case is recognized as presenting a broader collection and integration of arguments and evidence that describe, quantify and substantiate the safety of facility for the various stage of its development and operation. In turn, decisions regarding the development of new disposal facilities or the upgrading of existing facilities can be based on the safety case recognizing that such decision are made within a wider geo-political and socio-economic context.

Given the identified limitations of the ISAM assessment methodology and the lessons learnt during the ASAM project, as well as the importance and considerable international interest in the safe management and disposal of a wide range of radioactive wastes, it was recommended that a new programme of research should be established as a logical extension of the ISAM and ASAM projects and which seeks to improve the integration of the necessarily detailed safety assessment work within the safety case for the disposal facility, and give guidance on the provision of supporting information for 'real world' decisions on radioactive waste management and disposal.

The new programme will refine and extend the ISAM safety assessment methodology and facilitate discussions on safety cases and regulatory decision-making. The approach proposed is designed to ensure that the focus of the project remains on identifying credible solutions to safety assessment and safety case issues that can be used in practical decision-making. Four subject areas are proposed as the main components of the new programme: Safety case development; Decision-making support; Human intrusion and waste acceptance criteria; and Safety assessment with prioritisation.

Significant progress has been made in recent years in a number of countries that are either developing geological disposal facilities or contemplating their development. This has led to increasing interest worldwide in the demonstration of their safety and also to the development of harmonized approaches to such safety demonstration. These last years, an European Pilot Study on Demonstrating the Safety of Geological Disposal has intended to develop a consensual approach on regulatory expectations for the demonstration of the safety of geological disposal within the European region based on IAEA safety standards. Following this initiative, the IAEA has organized the International Project on Demonstrating the Safety of Geological Disposal (GEOSAF) to examine the evolution of arguments, assessments and supporting evidence developed to provide a reasonable level of assurance of safety to all interested parties. It gives particular attention to the systematic review of such arguments, assessments and supporting evidence by regulatory bodies. The main aim of GEOSAF is to work towards harmonization of approaches worldwide to demonstrate the safety of geological disposal. GEOSAF provides a global forum for exchanging experience and ideas between organizations and authorities responsible for such safety demonstration, and for related regulatory review and approval. GEOSAF encompasses all types of geological disposal facilities, including those designed for high level waste, spent fuel if declared as a waste, conditioned high level waste from reprocessing, longer lived intermediate level waste, and other waste not suitable for disposal in near surface facilities. 


\section{CONCLUSION}

International safety standards for the safety of radioactive waste disposal have undergone considerable development over the past decade and have evolved to provide a limited number of focused requirements germane to all types of disposal facilities. A suite of guidance documents are under development reflecting current practice for meeting these requirements for the different disposal options available both near surface and underground. The standards reflect the emerging consensus on the structure and content of safety cases for presenting the arguments in the support of the safety of disposal facilities together with supporting safety assessments providing quantitative evaluation of radiation doses and risks for the [post closure period. Guidance is also provided on approaches to ensuring an acceptable level of quality in the siting design construction and operation and in the conducting of safety assessment. Intercomparison projects are assisting with harmonization of approaches to use the standards and to demonstrate compliance with safety requirements and related quantitative safety criteria. The international standards and the harmonized methodologies for demonstrating compliance are increasingly providing a cornerstone for the global safety regime and its international peer review process.

\section{References}

[1] International Nuclear Safety Group, Strengthening the Global Nuclear Safety Regime, INSAG 21, IAEA, Vienna (2006).

[2] International Atomic Energy Agency, Fundamental Safety Principles, Safety Fundamentals, Safety Standards Series No. SF1, IAEA, Vienna (2006).

[3] International Atomic Energy Agency, Near Surface Disposal of Radioactive Waste, Safety Standards Series No. WS-R-1, IAEA, Vienna (1999).

[4] International Atomic Energy Agency, Geological Disposal of Radioactive Waste, IAEA Safety Standards Series No. WS-R-4, IAEA, Vienna (2006).

[5] International Commission on radiological Protection, Radiation Protection Recommendations as Applied to the Disposal of Long Lived Solid Radioactive Waste, ICRP Publication 81, Pergamon Press, Oxford and New York (2000).

[6] International Atomic Energy Agency, Safety Assessment Methodologies for Near Surface Disposal Facilities (ISAM), Vol. I - Review and enhancement of safety assessment approaches and tools; Vol. II - Tests Cases, IAEA, Vienna (2004). 